\title{
Maternal Demographics and Extremely Preterm Infant Mortality in the United States
}

Beau J Batton ${ }^{1 *}$, Reem Y Nubani ${ }^{1}$, Christopher P Burnett ${ }^{1}$, Steven J Verhulst ${ }^{2}$ and Daniel G Batton ${ }^{1}$

${ }^{1}$ Department of Pediatrics, Southern Illinois University School of Medicine, Springfield, Illinois, USA

${ }^{2}$ Department of Statistics and Epidemiology, Southern Illinois University School of Medicine, Springfield, Illinois, USA

\section{Abstract}

Background: The mortality rate for term infants varies by location and maternal demographics, but the relationship between these factors and the extremely preterm Infant Mortality Rate (IMR) may be different. Understanding the epidemiology of the extremely preterm IMR is important because infants born before 28 weeks gestation account for more than one-third of all infant deaths.

Objectives: 1) Estimate the extremely preterm IMR for different states and locations (urban versus rural county) of the United States; 2) evaluate the impact of maternal race and education on this IMR and; 3 ) investigate the timing of death for extremely preterm infants who die in the first year.

Methods: Data were analyzed from the National Center for Health Statistics to investigate the influence of birth location, maternal race, and maternal education on the IMR for infants born alive in the United States at 200/7-276/7 weeks gestation from 1995-2005.

Results: The IMR was 392/1,000 live births for the 306,502 extremely preterm infants investigated. The extremely preterm IMR varied by maternal race and was highest for infants born to White mothers (397, 95\% confidence interval (Cl): 395, 399) and lowest for those born to Black/African American mothers (386, 95\% Cl: (383, 389)). Rural county birth was associated with a higher extremely preterm IMR than urban county birth $(p=0.006)$. Maternal education had a bimodal relationship with the extremely preterm IMR such that the highest rates occurred with the least or greatest amount of education. With multi-variable analysis, birth in a rural county and maternal race negated the effects of maternal education on the extremely preterm IMR.

Conclusion: The extremely preterm IMR varies widely based on demographics known at the time of delivery. This variability is distinct from that observed for more mature infants and may partially explain differences in IMR across neonatal intensive care units.

Keywords: Maternal demographics; Extremely preterm infant mortality; United States (US)

\section{Introduction}

The infant mortality rate (IMR) in the United States steadily declined in the latter half of the twentieth century, particularly for preterm infants [1,2]. Reasons for this improvement in survival include the regionalization of perinatal care, the evolution of neonatal intensive care units, the increased use of prenatal steroids, and the development of surfactant therapy [3-7]. However, more recently the mortality rate for preterm infants has remained static as there has been little change in the last two decades [8,9]. During this same time period, the preterm birth rate has steadily increased [8-10] resulting in a significant rise in both the number of preterm infant births and deaths. Less than one percent of all births occur before 28 weeks gestational age (GA), but this population comprises a disproportionally high percentage of infant deaths-approximately one-third of all deaths in the first year [11]. The IMR varies widely between Neonatal Intensive Care Units (NICUs). This is considered to be partly a reflection of differences in neonatal demographic data [12]. However, the impact of demographics on the IMR specifically for extremely preterm infants in the United States has not been fully delineated and may differ from that of more mature infants. Since these infants represent a disproportionally high percentage of infant deaths, further examination of national epidemiologic variables on the extremely preterm IMR is important. The objectives of this study were to: 1) estimate the extremely preterm IMR for different states and locations (urban versus rural county) of the United States; 2) evaluate the impact of maternal race and education on this IMR and;
3) investigate the timing of death for extremely preterm infants who die in the first year.

\section{Methods}

Data were analyzed from the Centers for Disease Control and Prevention National Center for Health Statistics (NCHS) Linked Birth / Infant Death Records (wonder.cdc.gov/lbd) for all extremely preterm infants born alive at $20^{0 / 7}$ to $27^{6 / 7}$ weeks GA between January 1, 1995 and December 31, 2005 (the most recent year for which public data was available at the time of this analysis) [13]. During this time, the NCHS produced linked data in both birth cohort and period format. Period format data were used for this analysis. For example, the numerator for the 2005 period linked data represents all infant deaths occurring in 2005 (regardless of whether the infant was born in 2004 or 2005) and the denominator represents all infant births in

*Corresponding author: Beau J Batton, MD, Department of Pediatrics, Division of Neonatology, Southern Illinois University School of Medicine, P.O. Box 19676 Springfield, Illinois 62794, USA, Tel: 217-757-6429; Fax: 217-757-6844; E-mail: bbatton@siumed.edu

Received December 14, 2012; Accepted December 28, 2012; Published December 31, 2012

Citation: Batton BJ, Nubani RY, Burnett CP, Verhulst SJ, Batton DG (2013) Maternal Demographics and Extremely Preterm Infant Mortality in the United States. J Neonatal Biol 2:113. doi:10.4172/2167-0897.1000113

Copyright: @ 2013 Batton BJ, et al. This is an open-access article distributed under the terms of the Creative Commons Attribution License, which permits unrestricted use, distribution, and reproduction in any medium, provided the original author and source are credited. 
2005. Data were compiled from birth certificates for infants born alive in the United States and death certificates for infants who died prior to their first birthday. These certificates are linked by corresponding numbers. Birth certificates include the county of birth, the recorded $\mathrm{GA}$, and self-reported maternal information on the highest level of education obtained ( $0-8$ years, 9-11 years, 12 years, 13-15 years, $\geq 16$ years, not stated, or excluded) and race (American Indian/ Alaskan native, Asian/Pacific Islander, Black/African American, or White). Data for American Indian/Alaskan native infants were not included in this analysis due to concerns about underreporting or misclassification of deaths of very low birth weight infants in these populations [14]. During the study years, births in the United States were recorded using either the 1989 revised birth certificate or the 2003 revised birth certificate. Transition from the 1989 to the 2003 birth certificate occurred during 2004 and 2005. The 1989 revised birth certificate recorded the "clinical estimate of gestational age" and the 2003 revised birth certificate recorded the "obstetrician's estimate of gestation." Standard practice in the United States during this time was to determine the GA based on the mother's Last Menstrual Period (LMP) and to revise it based on the obstetrician's examination or early prenatal ultrasound if indicated. When early ultrasound is not performed and either the LMP is uncertain or the LMP based GA is inconsistent with the infant's birth weight or physical examination, then examination of the infant is used to determine the GA. Information on early prenatal ultrasound is not recorded on birth certificates, but in the NCHS database examination of the infant was used to estimate the GA for 4.6 to $5.9 \%$ of all births annually from 1995 to 2005 [13]. The 20-27 weeks GA range was chosen because mortality data specific to each week of gestation for preterm infants was not available at all prior to 1999 and only inconsistently from 2000-2005 because the NCHS database suppresses results when the number of infants who fit a specific data query are low in order to protect confidentiality. The state and county of birth were reported for all infants. Within a given state, births occurring in any county with a total population less than 250,000 people are reported under "Unidentified County" to protect personal privacy. Urban counties were those with a population of more than 250,000 . The postnatal age at death was reported as: less than one hour, 1-23 hours, 24 hourssix days, 7-27 days, or 28-365 days. The extremely preterm IMR was defined as the number of deaths in the first 365 days/1,000 live extremely preterm infant births.

Statistical analysis was performed using SAS software, version 9.1.3 (Cary, North Carolina). Regression analysis was used to compare changes in the ratio of the annual number of births at all GA ranges versus extremely preterm infant births over time. Pearson correlation coefficients were used to analyze the relationship between the extremely preterm infant birth rate and the IMR for urban counties and to analyze the relationship between population, extremely preterm infant birth rate, and the IMR for states. The Chi Squared test was used to compare mortality rates across different maternal races and educational levels as well as urban versus rural place of birth. Multiple logistic regression analysis was used to investigate the relationship between maternal education, maternal race, and location of birth (urban versus rural county) on the extremely preterm IMR. This study was exempt from Institutional Review Board approval by Southern Illinois University School of Medicine because only deidentified data was utilized.

\section{Results}

There were 44,020,325 births during the study period, including
$306,502(0.70 \%)$ births at $20^{0 / 7}$ to $27^{6 / 7}$ weeks GA (Table 1$)$. The annual number of infants born at 20-27 weeks GA increased by $14 \%$ during the study period compared to a six percent increase for infants born at all gestations $(\mathrm{p}=0.012$ ). There were 309,773 infant deaths during the study period for an overall IMR of 7.0/1,000 live births, including 120,218 (39\%) deaths of infants born at 20-27 weeks GA (extremely preterm IMR: 392). The annual IMR for infants of all GA decreased from 7.6 in 1995 to 6.9 in 2005 ( $<<0.001,95 \%$ confidence interval (CI): $1.086,1.122$ ) and the annual extremely preterm IMR decreased from 403 in 1995 to 385 in 2005 ( $<<0.001,95 \%$ CI: (1.077, 1.114)). For each study year, infants born 20-27 weeks GA accounted for at least $36 \%$ of all infant deaths. Most infant deaths occurred in the first postnatal week: $24 \%$ in the first hour, $40 \%$ from hour one to 24 , and $14 \%$ after 24 hours but in the first seven days. Additionally, $12 \%$ of deaths occurred from postnatal day seven to 28 , and $10 \%$ from postnatal day 29 to 365 .

The state specific extremely preterm IMR ranged from 309 (Alaska) to 477 (Figure 1). There was not a regional distribution of the states with the highest or lowest extremely preterm IMR. There was not a statistically significant relationship between the state extremely preterm IMR and either the state population $(\mathrm{p}=0.31)$ or the state preterm birth rate $(\mathrm{p}=0.17)$.

Significant differences in the extremely preterm IMR were noted related to maternal race, education, and birth location (Table 2). The

\begin{tabular}{|l|l|l|l|l|l|l|}
\hline Year & $\begin{array}{l}\text { Births } \\
\text { All GA }\end{array}$ & $\begin{array}{l}\text { Births } \\
\mathbf{2 0 - 2 7} \text { weeks GA* }\end{array}$ & $\begin{array}{l}\text { Deaths } \\
\text { All GA }\end{array}$ & $\begin{array}{l}\text { Deaths } \\
\mathbf{2 0 - 2 7} \text { weeks } \\
\text { GA† }\end{array}$ & $\begin{array}{l}\text { IMR } \\
\text { All GA }\end{array}$ & $\begin{array}{l}\text { IMR } \\
\mathbf{2 0 - 2 7} \\
\text { weeks GA }\end{array}$ \\
\hline 1995 & $3,899,589$ & $26,400(0.68 \%)$ & 29,505 & $10,653(36 \%)$ & 7.6 & 403 \\
\hline 1996 & $3,891,494$ & $26,382(0.68 \%)$ & 28,419 & $10,584(37 \%)$ & 7.3 & 401 \\
\hline 1997 & $3,880,894$ & $26,920(0.69 \%)$ & 27,968 & $10,573(38 \%)$ & 7.2 & 392 \\
\hline 1998 & $3,941,553$ & $27,826(0.71 \%)$ & 28,325 & $10,837(38 \%)$ & 7.2 & 389 \\
\hline 1999 & $3,959,417$ & $27,795(0.70 \%)$ & 27,864 & $10,824(39 \%)$ & 7.0 & 389 \\
\hline 2000 & $4,058,882$ & $27,731(0.68 \%)$ & 27,960 & $10,787(39 \%)$ & 6.9 & 388 \\
\hline 2001 & $4,026,036$ & $27,800(0.69 \%)$ & 27,523 & $10,726(39 \%)$ & 6.8 & 385 \\
\hline 2002 & $4,021,825$ & $28,093(0.70 \%)$ & 27,970 & $11,085(40 \%)$ & 7.0 & 394 \\
\hline 2003 & $4,090,007$ & $28,484(0.70 \%)$ & 27,995 & $11,289(40 \%)$ & 6.8 & 396 \\
\hline 2004 & $4,112,055$ & $29,103(0.71 \%)$ & 27,860 & $11,298(41 \%)$ & 6.8 & 388 \\
\hline 2005 & $4,138,573$ & $29,968(0.72 \%)$ & 28,384 & $11,562(41 \%)$ & 6.9 & 385 \\
\hline Total & $44,020,325$ & $306,502(0.70 \%)$ & 309,773 & $120,218(39 \%)$ & 7.0 & 392 \\
\hline
\end{tabular}

$\mathrm{GA}=$ Gestational Age; IMR=Infant Mortality Rate (\# deaths per 1,000 live births); *percentage refers to percent of all births which occurred at 20-27 weeks GA; tpercentage refers to percent of all deaths in which the infant was born at 20-27 weeks gestation

Table 1: Births, deaths and mortality rates for infants of all gestations and infants born 20-27 weeks gestation from 1995 to 2005.

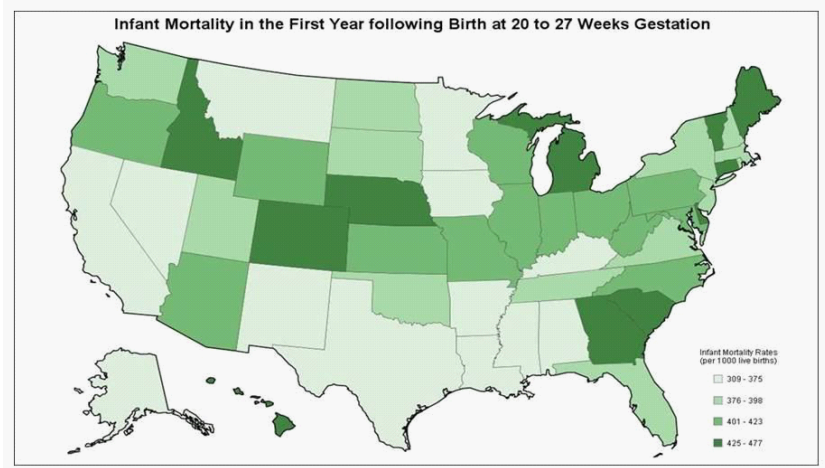

Figure 1: State extremely preterm infant mortality rates (deaths/1000 live births) in the United States from 1995 to 2005. 


\begin{tabular}{|l|l|}
\hline Maternal Demographic & \multicolumn{2}{l|}{ Extremely Preterm IMR (95\% CI) } \\
\hline Education Level: & $418(410,427)$ \\
\hline $0-8$ years & $369(365,373)$ \\
\hline 9-11 years & $388(385,391)$ \\
\hline 12 years & $387(383,391)$ \\
\hline $13-15$ years & $393(388,397)$ \\
\hline$\geq 16$ years & \\
\hline Race: & $391(381,400)$ \\
\hline Asian/Pacific Islander & $386(383,389)$ \\
\hline Black/African American & $397(395,399)$ \\
\hline White & \\
\hline Place of Residence: & $393(389,395)$ \\
\hline Rural county & $380(378,382)$ \\
\hline Urban county &
\end{tabular}

IMR=Infant Mortality Rate (\# deaths/1,000 extremely preterm live births); $\mathrm{Cl}=$ Confidence Interval

Table 2: Extremely preterm infant mortality rates with $95 \%$ confidence intervals for different maternal demographic data.

\begin{tabular}{|c|c|c|c|}
\hline Maternal Race & $\begin{array}{l}\text { Maternal Education } \\
\text { Level }\end{array}$ & $\begin{array}{l}\text { Location of } \\
\text { Birth }\end{array}$ & $\begin{array}{l}\text { Extremely } \\
\text { Preterm IMR }\end{array}$ \\
\hline Black/African American & 9-11 years & Urban & 343 \\
\hline Black/African American & $0-8$ years & Rural & 356 \\
\hline White & $0-8$ years & Urban & 363 \\
\hline Black/African American & 9-11 years & Rural & 369 \\
\hline White & 9-11 years & Urban & 374 \\
\hline Black/African American & $13-15$ years & Urban & 377 \\
\hline Black/African American & 12 years & Urban & 379 \\
\hline Black/African American & $0-8$ years & Urban & 383 \\
\hline White & $\geq 16$ years & Urban & 384 \\
\hline Asian/Pacific Islander & $\geq 16$ years & Urban & 385 \\
\hline White & 9-11 years & Rural & 387 \\
\hline White & $13-15$ years & Urban & 387 \\
\hline Black/African American & 12 years & Rural & 389 \\
\hline White & $0-8$ years & Rural & 389 \\
\hline White & 12 years & Urban & 389 \\
\hline Asian/Pacific Islander & 9-11 years & Urban & 390 \\
\hline White & $13-15$ years & Rural & 391 \\
\hline White & $\geq 16$ years & Rural & 393 \\
\hline Asian/Pacific Islander & $13-15$ years & Urban & 397 \\
\hline Black/African American & $\geq 16$ years & Urban & 397 \\
\hline Black/African American & $13-15$ years & Rural & 398 \\
\hline Asian/Pacific Islander & $0-8$ years & Urban & 398 \\
\hline White & 12 years & Rural & 399 \\
\hline Asian/Pacific Islander & 12 years & Urban & 404 \\
\hline Asian/Pacific Islander & 9-11 years & Rural & 413 \\
\hline Asian/Pacific Islander & 12 years & Rural & 420 \\
\hline Black/African American & $\geq 16$ years & Rural & 423 \\
\hline Asian/Pacific Islander & $0-8$ years & Rural & 463 \\
\hline Asian/Pacific Islander & $13-15$ years & Rural & 474 \\
\hline Asian/Pacific Islander & $\geq 16$ years & Rural & 526 \\
\hline
\end{tabular}

Table 3: Extremely preterm infant mortality rates based on maternal race, maternal education level, and location of birth. IMR=Infant Mortality Rate.

highest IMR occurred in extremely preterm infants of White mothers while the lowest was in extremely preterm infants of Black/African American mothers. The years of maternal education had a bimodal relationship with the extremely preterm IMR such that the highest rates occurred with the least or greatest amount of education. Rural county birth was associated with a significantly higher extremely preterm IMR than urban county $(\mathrm{p}=0.006)$ birth and this was true for all races: Asian/Pacific Islander (464 versus 396, $\mathrm{p}<0.001$; Odds Ratio (OR): 1.32, 95\% CI: (1.18, 1.48)), Black/African American (387 versus
373, p<0.001; OR: 1.07, 95\% CI: $(1.04,1.09)$ ), or White (394 versus 382, $\mathrm{p}<0.001$; OR: $1.05,95 \%$ CI: $(1.03,1.07))$. Table 3 demonstrates the variability in the extremely preterm IMR by maternal race, maternal education level, and location of birth. For extremely preterm infants of Asian/Pacific Islander mothers with the highest levels of education (13-15 years and $\geq 16$ years), the relative mortality risk was $1.37(95 \%$ CI: $(1.04,1.80))$ and 1.77 (95\% CI: $(1.44,2.17))$, respectively, following rural versus urban county birth. Extremely preterm infants of Black/ African American mothers had a significantly higher IMR after birth in a rural versus urban county for all maternal education levels except the lowest one (zero to eight years). Extremely preterm infants of White mothers also had a higher IMR after rural versus urban birth for maternal education levels $\leq 12$ years. With multi-variable analysis, birth in a rural county and maternal race were mostly strongly associated with the extremely preterm IMR and these two factors negated the effects of maternal education.

\section{Discussion}

Studies of more mature infants suggest the overall IMR (deaths/1,000 live births for infants at all gestations) varies by location of birth and maternal demographic data [10,15-20]. However, there are substantial differences in how these factors seem to impact the overall IMR versus the extremely preterm IMR. Previous studies have demonstrated significant state variation in the overall IMR $[8,10,15,16]$. While these reports included the IMR for late preterm (birth at 3436 weeks GA) or very low birth weight ( $<1500$ grams) infants, data specific to the extremely preterm infant population was not reported. State ranking by extremely preterm IMR was significantly different than ranking by overall IMR. For example, in this study the extremely preterm IMR in Louisiana was in the lowest quartile, but that state had the highest overall IMR [8]. Conversely, Nebraska State had an extremely preterm IMR in the highest quartile in the current study despite the ninth lowest overall IMR [8]. In addition, the regional disparity in the overall IMR reported previously [16] was not noted for extremely preterm infants. These differences may be explained by variability in population demographics, the extremely preterm birth rate, access to specialized healthcare for pregnant women and extremely preterm infants, the time frame investigated $[8,16]$, the percentage of infants with social and financial disadvantage when extremely preterm birth occurs $[15,16]$, and state variation in the rate of misclassification of early deaths [17].

Similar to the overall IMR, the extremely preterm IMR was higher in rural counties across the United States compared to urban ones $[18,21]$. In a recent study investigating the overall IMR in Texas from 1990 to 2004, the authors noted that the county specific IMR was associated with primary care physician supply and county median income index [21]. A higher extremely preterm IMR in rural counties is likely also related to limited access to the appropriate healthcare needed to optimally manage these critically ill infants and their mothers during the perinatal period [19]. Other contributing factors may include limited access to physicians who provide routine prenatal care, disparities in family income, differences in racial composition, and a lower rate of birth at a facility with a level III NICU [18-20].

The overall IMR has been higher for Black/African American infants compared to White infants for at least the last fifty years with little change $[8,10,18]$. In this study, differences in the extremely preterm IMR also occurred across races, but in a different patternBlack/African American infants had a significantly lower IMR than White infants. This may be related to racial differences in the rate of intubation and resuscitation of periviable infants [21], a lower 
Citation: Batton BJ, Nubani RY, Burnett CP, Verhulst SJ, Batton DG (2013) Maternal Demographics and Extremely Preterm Infant Mortality in the United States. J Neonatal Biol 2:113. doi:10.4172/2167-0897.1000113

Page 4 of 5

incidence of multiple gestations in the Black/African American population [22], or fewer respiratory problems such as respiratory distress syndrome or bronchopulmonary dysplasia [23]. Black/ African American infants may have a lower extremely preterm IMR, but a higher overall IMR, because extremely preterm birth occurs more frequently in the Black/African American population $[8,10,24]$ and therefore has a larger impact on the overall IMR compared to White infants. Other potential explanations are the higher rates of sudden infant death syndrome and fatal injuries in the Black/African American population $[8,24]$ causes death in which the infant is more often term or late preterm than extremely preterm.

As with the overall IMR, there are significant interactions between location of birth and maternal demographics which affect the extremely preterm IMR. The impact of maternal race or education on the extremely preterm IMR is overshadowed by the location of birth for some, but not all, races at some, but not all, education levels. State variations in race and population density also make it challenging to identify specific populations with a high extremely preterm IMR. In addition, attempts to decrease this IMR may best focus on areas with the potential for the largest impact, not necessarily those with the highest IMR. For example, Vermont had the highest extremely preterm IMR among states, but also had the fewest deaths at these gestations during the years investigated-only 165 . Conversely, Texas had the third lowest extremely preterm IMR (331), but the second highest number of deaths (8495). Hence, a slight improvement in the extremely preterm IMR in Texas would have a much more dramatic effect on the national extremely preterm IMR than a large improvement in Vermont even though extremely preterm infants in Vermont may be at greater risk of dying.

The wide variation in the extremely preterm IMR between NICUs is most likely due to many factors, including the previously mentioned factors which contribute to state variability in the same IMR. An additional factor is that some NICUs are more likely to resuscitate these infants than others. Current reported approaches range from universal resuscitation of all infants born at $\geq 23^{0 / 7}$ weeks GA [25] to selective resuscitation for infants born as late as $25^{6 / 7}$ weeks GA [26]. Tyson et al. have investigated numerous newborn factors (gender, birth-weight, singleton, exposure to prenatal steroids), in addition to GA, which significantly contribute to mortality [27]. Data from this study suggest maternal demographic data are also important. The IMR is often considered an indicator of the quality of care a NICU provides [28]. The data from this study suggests such an approach is not valid unless differences in maternal demographics and location of birth are considered as well.

Limitations to this study include the validity of GA assignment for a small percentage of infants [13], the inability to link two to three percent of infant deaths to their corresponding birth certificates (although the data are weighted up to the complete count of infant deaths in the United States in order to account for this) $[8,13]$ and potential misclassification of some fetal deaths as early infant deaths [17]. These limitations are related to the nature of the data set but are unlikely to be significantly different between study years or maternal demographic data. Implications for clinical practice are limited because results are from non-randomized population based data. Study strengths include the large number of births and infant deaths, the ability to link a very high rate of infant deaths to birth data (>98\%) [13], data specific to the extremely preterm infant population, and comprehensive records for the United States population provided by the NCHS.

\section{Conclusion}

In conclusion, the extremely preterm IMR in the United States from 1995 to 2005 varied significantly with location of birth, maternal race, and maternal education level. This variability differs from that of more mature infants. Undoubtedly, the interactions between these factors and others are complex and most likely contribute to differences in mortality between NICUs.

\section{References}

1. Division of Reproductive Health, National Center for Chronic Disease Prevention and Health Promotion (1999) Achievements in public health, 1900-1999: healthier mothers and babies. MMWR 48: 849-858.

2. Guyer B, Freedman MA, Strobino DM, Sondik EJ (2000) Annual summary of vital statistics: Trends in the health of Americans during the 20th century. Pediatrics 106: 1307-1317.

3. McCormick MC, Shapiro S, Starfield BH (1985) The regionalization of perinatal services. Summary of the evaluation of a national demonstration program. JAMA 253: 799-804.

4. Liggins GC, Howie RN (1972) Controlled trial of antepartum glucocorticoid treatment for prevention of the respiratory distress syndrome in premature infants. Pediatrics 50: 515-525.

5. Warner B, Musial JM, Chenier T, Donovan E (2004) The effect of birth hospital type on the outcome of very low birth weight infants. Pediatrics 113: 35-41.

6. Doyle LW, Kitchen WH, Ford GW, Rickards AL, Lissenden JV, et al. (1986) Effects of antenatal steroid therapy on mortality and morbidity in very low birth weight infants. J Pediatr 108: 287-292.

7. Horbar JD, Soll RF, Sutherland JM, Kotagal U, Philip AG, et al. (1989) A multicenter randomized, placebo-controlled trial of surfactant therapy for respiratory distress syndrome. N Engl J Med 320: 959-965.

8. Mathews TJ, Mac Dorman MF (2008) Infant mortality statistics from the 2005 period linked birth/infant death data set. National Vital Statistics Reports 57: $1-32$.

9. Mac Dorman MF, Mathews TJ (2009) The challenge of infant mortality: have we reached a plateau? Public Health Rep 124: 670-681.

10. Mathews TJ, Minino AM, Osterman M, Strobino D, Guyer B (2011) Annual summary of vital statistics: 2008 . Pediatrics 127: 146-157.

11. Batton B, Burnett C, Verhulst S, Batton D (2011) Extremely preterm infant mortality rates and cesarean deliveries in the United States. Obstet Gynecol 118: 43-48.

12. Holmstrom ST, Phibbs CS (2009) Regionalization and mortality in neonatal intensive care. Pediatr Clin North Am 56: 617-630.

13. United States Department of Health and Human Services, Centers for Disease Control and Prevention. National Center for Health Statistics, Division of Vital Statistics System.

14. Heck KE, Schoendorf KC, Parker J (1999) Are very low birthweight births among American Indians and Alaska Natives underregistered? Int J Epidemiol 28: 1096-1101.

15. O'Hare WP, Ritualo AR (2000) Kids count: identifying and helping America's most vulnerable. Stat Bull Metrop Insur Co 81: 26-32.

16. Goldhagen J, Remo R, Bryant T, Wludyka P, Dailey A, et al. (2005) The health status of Southern children: a neglected regional disparity. Pediatrics 116: e746-e753.

17. Ehrenthal DB, Wingate MS, Kirby RS (2011) Variation by state in outcomes classification for deliveries less than $500 \mathrm{~g}$ in the United States. Matern Child Health J 15: 42-48.

18. Chabot MJ, Garfinel J, Pratt MW (1975) Urbanization and differentials in white and nonwhite infant mortality. Pediatrics 56: 777-781.

19. Lairmore WL, Davis A (1995) Relation of infant mortality to the availability of maternity care in rural Florida. J Am Board Fam Pract 8: 392-399.

20. Olson ME, Diekema D, Elliott BA, Renier CM (2010) Impact of income and income inequality on infant health outcomes in the United States. Pediatrics 126: $1165-1173$. 
Citation: Batton BJ, Nubani RY, Burnett CP, Verhulst SJ, Batton DG (2013) Maternal Demographics and Extremely Preterm Infant Mortality in the United States. J Neonatal Biol 2:113. doi:10.4172/2167-0897.1000113

Page 5 of 5

21. Edmonds BT, Fager C, Srinivas S, Lorch S (2011) Racial and ethnic differences in use of intubation for periviable neonates. Pediatrics 127: e1120-e1127.

22. Petrova A, Mehta R, Anwar M, Hiatt M, Hegyi T (2003) Impact of race and ethnicity on the outcome of preterm infants below 32 weeks gestation. J Perinatol 23: 404-408.

23. Akram Khan M, Kuzma-O'Reilly B, Brodsky NL, Bhandari V (2006) Sitespecific characteristics of infants developing bronchopulmonary dysplasia. J Perinatol 26: 428-435.

24. Kitsantas P, Gaffney KF (2010) Racial/ethnic disparities in infant mortality. J Perinat Med 38: 87-94.
25. Batton D (2009) Antenatal Counseling Regarding Resuscitation at an Extremely Low Gestational Age. Pediatrics 124: 422-427

26. Kaempf JW, Tomlinson M, Arduza C, Anderson S, Campbell B, et al. (2006) Medical staff guidelines for periviability pregnancy counseling and medical treatment of extremely premature infants. Pediatrics 117: 22-29.

27. Tyson JE, Parikh NA, Langer J, Green C, Higgins RD (2008) Intensive care for extreme prematurity-moving beyond gestational age. N Engl J Med 358: 1672-1681.

28. Vermont Oxford Network referenced publications. 